\title{
Liquid Membrane Electrochemical Etching: Twin Nano-Tips Fabrication for Micromachining
}

\author{
Yufeng Wang ${ }^{1}$, Yongbin Zeng ${ }^{1,2, *}$, Xiaofeng Wang ${ }^{1}$, Ningsong $Q u^{1,2}$, Di Zhu ${ }^{1,2}$ \\ ${ }^{1}$ College of Mechanical and Electrical Engineering, Nanjing University of Aeronautics and \\ Astronautics, Nanjing, China, 210016 \\ ${ }^{2}$ Jiangsu Key Laboratory of Precision and Micro-Manufacturing Technology, Nanjing, China, 210016 \\ *E-mail: binyz@nuaa.edu.cn
}

doi: $10.20964 / 1009103$

Received: 24 December 2015 / Accepted: 21 February 2016 / Published: 1 April 2016

\begin{abstract}
Nano-electrodes are essential components in electrochemical micromachining, allowing high machining accuracy and minimum machining size. Liquid membrane electrochemical etching processes twin nano-electrodes with parabolic upper and conical lower nano-electrodes simultaneously. After the lower tip drops off, blunting due to residual current increases the diameter of the upper tip. This blunting can be decreased by cutting off the residual current in $5 \mathrm{~ms}$ with a newly developed control strategy. Experimental results indicate that the diameters of both nano-electrodes decrease with the use of lower voltage and electrolyte concentration and shorter lower-end length. To avoid low etching efficiency or a boiling effect, appropriate parameters should be selected. Blunting can also be reduced by using lower voltage and electrolyte concentration. Twin nano-electrodes with upper- and lower-tip diameters of 110 and $80 \mathrm{~nm}$, respectively, have been fabricated and used to make micro-holes of $2 \mu \mathrm{m}$ diameter by electrochemical micro-drilling.
\end{abstract}

Keywords: Electrochemical etching; Liquid membrane; Nanoelectrode; Blunting; Cut off

\section{FULL TEXT}

(C) 2016 The Authors. Published by ESG (www.electrochemsci.org). This article is an open access article distributed under the terms and conditions of the Creative Commons Attribution license (http://creativecommons.org/licenses/by/4.0/). 